\title{
Corrigendum: Rag defects and thymic stroma: Iessons from animal models
}

\author{
Veronica Marrella ${ }^{1,2}$, Pietro Luigi Poliani ${ }^{3}$, Luigi Daniele Notarangelo ${ }^{4}$, Fabio Grassi ${ }^{5}$ and Anna Villa ${ }^{1,2} *$ \\ ${ }^{1}$ Milan Unit, Institute of Genetics and Biomedic Research, National Research Council, Milan, Italy \\ ${ }^{2}$ Istituto Clinico Humanitas, Istituto di Ricovero e Cura a Carattere Scientifico, Rozzano, Italy \\ ${ }^{3}$ Pathology Unit, Department of Molecular and Translational Medicine, University of Brescia, Brescia, Italy \\ ${ }^{4}$ Division of Immunology, Boston Children's Hospital, Boston, MA, USA \\ ${ }^{5}$ Institute for Research in Biomedicine, Bellinzona, Switzerland \\ *Correspondence: anna.villa@hsr.it \\ Edited and reviewed by: \\ Claudio Pignata, University of Naples Federico II, Italy
}

Keywords: hymus, rag deficiency, omenn and leaky SCID models, central tolerance, thymic reconstitution, thymic crosstalk

\section{A corrigendum on}

Rag defects and thymic stroma: lessons from animal models

by Marrella V, Poliani PL, Notarangelo LD,

Grassi F, Villa A. Front Immunol (2014)

5:259. doi:10.3389/fimmu.2014.00259

Author list for the article "Rag defects and thymic stroma: lessons from animal models" should be as follows:

Veronica Marrella ${ }^{1,2}$, Pietro Luigi Poliani ${ }^{3}$, Luigi Daniele Notarangelo ${ }^{4}$, Fabio Grassi $^{5}$, and Anna Villa ${ }^{1,2^{*}}$
${ }^{1}$ Milan Unit, Institute of Genetics and Biomedic Research, National Research Council, Milan, Italy

${ }^{2}$ Istituto Clinico Humanitas, Istituto di Ricovero e Cura a Carattere Scientifico, Rozzano, Italy

${ }^{3}$ Pathology Unit, Department of Molecular and Translational Medicine, University of Brescia, Brescia, Italy

${ }^{4}$ Division of Immunology, Boston Children's Hospital, Boston, MA, USA

${ }^{5}$ Institute for Research in Biomedicine, Bellinzona, Switzerland

The original article has been updated.

Conflict of Interest Statement: The authors declare that the research was conducted in the absence of any commercial or financial relationships that could be construed as a potential conflict of interest.

Received: 11 August 2014; accepted: 11 August 2014; published online: 25 August 2014.

Citation: Marrella V, Poliani PL, Notarangelo LD, Grassi F and Villa A (2014) Corrigendum: Rag defects and thymic stroma: lessons from animal models. Front. Immunol. 5:407. doi: 10.3389/fimmu.2014.00407

This article was submitted to T Cell Biology, a section of the journal Frontiers in Immunology.

Copyright $\odot 2014$ Marrella, Poliani, Notarangelo, Grassi and Villa. This is an open-access article distributed under the terms of the Creative Commons Attribution License (CC BY). The use, distribution or reproduction in other forums is permitted, provided the original author(s) or licensor are credited and that the original publication in this journal is cited, in accordance with accepted academic practice. No use, distribution or reproduction is permitted which does not comply with these terms. 